\title{
ДИСТАНЦИОННАЯ ЗАНЯТОСТЬ: ОЦЕНКА И НАПРАВЛЕНИЯ РЕГУЛИРОВАНИЯ
}

\author{
Е. С. Дашкова, В. Е. Звягинцева
}

Воронежский государственный университет

Поступила в редакцию 15 января 2020 г.

\begin{abstract}
Аннотация: обосновывается актуальность проблемы исследования и оценки дистанционной занятости в России. Представляются результаты опроса дистанционных работников, проводятся их анализ и оценка. На основании сформулированных выводов предлагаются основные направления совериенствования дистанциинной занятости в регионе, нацеленные на укрепление дистаниионного труда в формальном секторе.
\end{abstract}

Ключевые слова: занятость населения, нестандартные формы занятости населения, дистаниионная занятость, политика занятости населения.

\begin{abstract}
: the article substantiates the relevance of the problem of research and evaluation of distance employment in Russia. The results of the survey of remote workers are presented, their analysis and evaluation is carried out. Based on the findings, the main directions for improving distance employment in the region are proposed, aimed at strengthening distance work in the formal sector.
\end{abstract}

Key words: employment, non-standard forms of employment, remote employment, employment policy.

Современный рынок труда в России характеризуется диверсификацией форм занятости. Возникновение и распространение дистанционного труда в РФ, как и в других странах, во многом обусловлены глобализацией, информатизацией общества и ориентиром на цифровизацию. Соглашаясь с позицией А. А. Федченко, Ю. Г. Одегова, Л. С. Бабыниной, можно утверждать, что именно четвертая промышленная революция стала катализатором цифровизации, в условиях которой роль дистанционной занятости резко возрастает $[1,2]$. Гибкие формы занятости, к которым относится дистанционный труд, отличаются иным в сравнении со стандартной занятостью характером трудовой деятельности, появлением новых требований к работникам и результатам их труда, а также способствуют распространению нетрадиционных систем оплаты труда, развитию современных способов и методов организации труда. В таких условиях сложно организовывать трудовой процесс в соответствии с традиционными подходами. Следовательно, исследование особенностей развития дистанционной занятости в России, ее анализ и оценка на сегодняшний день достаточно востребованы для науки и практики управления занятостью.

Явление дистанционной занятости на настоящее время изучено «поверхностно», так как отсутствуют комплексные исследования специфики дистанционного труда в России, не определены количественные

(С) Дашкова Е. С., Звягинцева В. Е., 2020 и качественные оценки данного явления, отсутствует соответствующая объективная статистика дистанционной занятости. Поэтому с целью более глубокого и детального исследования дистанционной занятости в 2019 г. нами проведено социологические исследование, в ходе которого было опрошено 196 человек, работающих дистанционно. Исследование проводилось методом «снежного кома» и онлайн-анкетирования на платформе Survio. Метод «снежного кома» предполагает поиск первичных респондентов, а те в свою очередь помогают в поиске последующих анкетируемых. То есть первичная группа создает своего рода «снежный ком», который «обрастает» людьми. Метод онлайн-анкетирования заключается в поиске респондентов в тематических группах в социальных сетях. Использование двух методов поиска респондентов реализовывалось для поддержания репрезентативности выборки на достаточно высоком уровне. Также для этой цели метод «снежного кома» ограничивался третьим шагом.

По итогам опроса был проведен его анализ. Разделение респондентов по полу выглядит следующим образом: женщины - 61 \%, мужчины - $39 \%$; по возрастным группам: до 30 лет $-47 \%, 30$ 44 года - $38 \%, 45-59$ лет - $10 \%, 60$ и старше - 5\%. Распределение опрошенных по уровню образования дало следующие результаты:

$$
\begin{aligned}
& \text { - неполное среднее - } 1 \% \text {; } \\
& \text { - общее среднее - } 7 \% \text {; } \\
& \text { - незаконченное высшее - } 11 \% \text {; }
\end{aligned}
$$


- высшее - $78 \%$;

- имеют ученую степень - $2 \%$.

Таким образом, социальный портрет дистанционно занятого - это женщина в возрасте до 30 лет, имеющая высшее образование.

В ходе исследования дистанционной занятости было выяснено, что всех работающих участников опроса можно разделить на четыре группы в зависимости от времени их вовлеченности в дистанционную работу (рис. 1).
Из полученных данных можно констатировать, что от общего количества опрошенных $69 \%$ работают дистанционно до 5 лет; 27 \% вовлечены в дистанционную занятость от 5 до 10 лет, $3 \%$ от 10 до 15 лет и лишь $1 \%$ - свыше 15 лет. Следовательно, дистанционный труд - относительно новое явление на российском рынке труда и находится на стадии становления.

На рис. 2 приведены наиболее распространенные сферы труда дистанционно занятых.

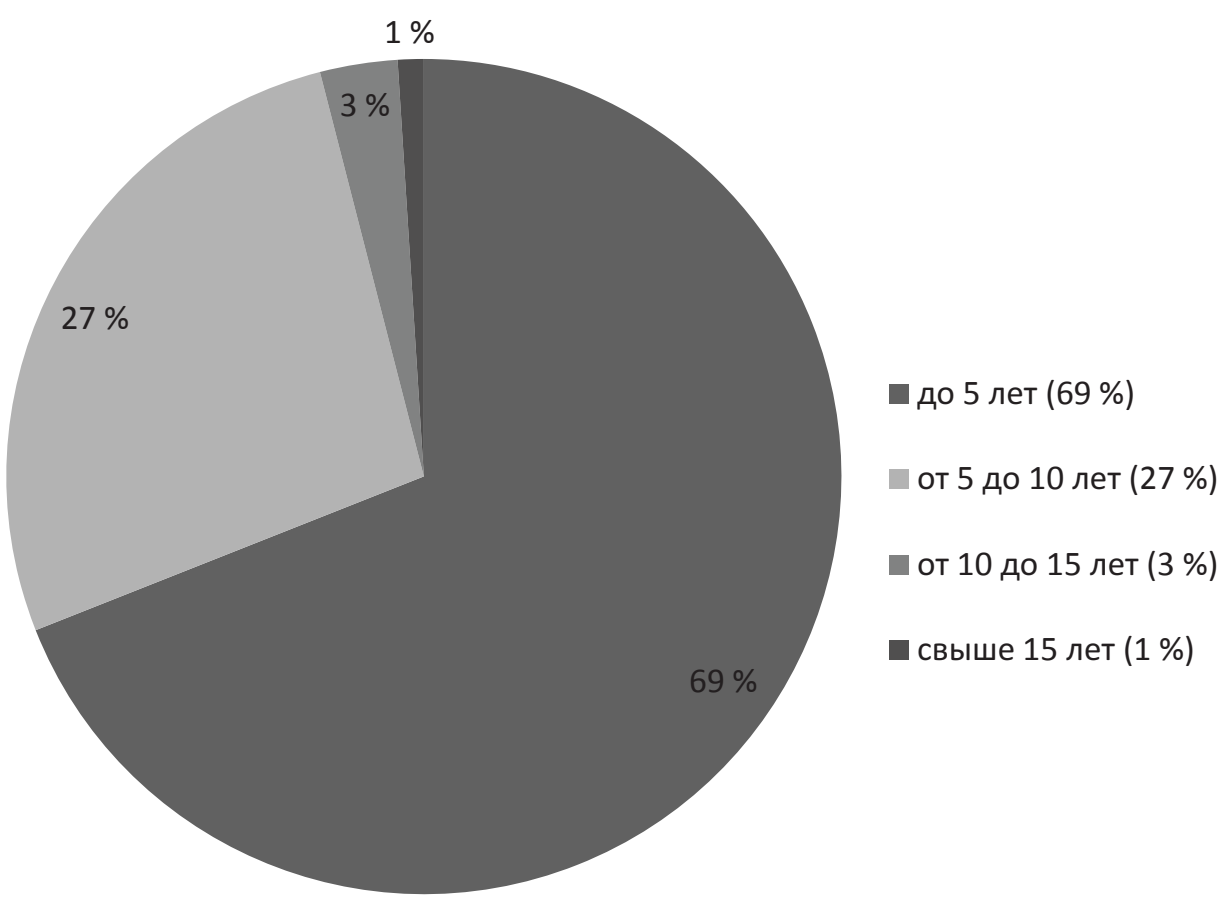

Рис. 1. Распределение ответов на вопрос «Как давно Вы работаете дистанционно?», в \%

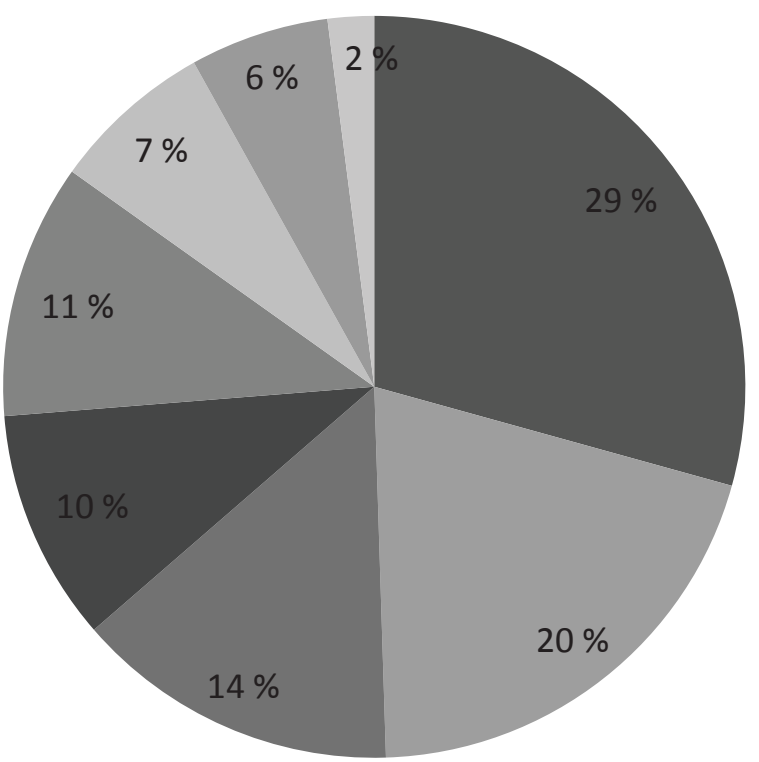

IT, программирование (29\%)

- продажи (20\%)

иное (14\%)

п финансы, бухгалтерия (10\%)

пнтернет-занятость (копирайтинг, рерайтинг; интернет-маркетинг) (11\%)

пизайн (7 \%)

ш службы клиентской поддержки (6 \%)

страхование (2\%)

Рис. 2. Распределение ответов на вопрос «В какой сфере Вы являетесь дистанционно занятым?», в \% 
Наиболее распространёнными сферами занятости дистанционных работников являются IT, программирование, продажи, финансы и бухгалтерия. Очевидно, что это те сферы, которые предполагают гибкую организацию трудовых процессов, гибкий штат, удаленное взаимодействие нанимателей и работников.

Согласно итогам опроса только у $34 \%$ респондентов дистанционная занятость оформлена трудовым договором, т. е. регулируется в рамках правового поля. У большинства работников дистанционная занятость не оформлена трудовым договором, что свидетельствует о наличии проблем в её нормативно-правовом регулировании, отсутствии официальной статистики и мониторинга.

Данные о том, как опрошенные оценивают уровень оплаты труда по сравнению с их офисными коллегами (стандартно занятыми), выполняющими аналогичную работу, приведены в табл. 1.

Исходя из представленных в таблице данных, можно констатировать, что проблем с оплатой труда для большинства дистанционных работников не имеется, так как 50 \% указали, что заработная плата «наравне» со стандартно занятыми, и $22 \%$ больше, чем у стандартно занятых.

Анализируя ответы респондентов о причинах выбора дистанционной занятости, отметим, что наиболее значимыми из них являются гибкое рабочее время (54\%), дополнительный заработок (38 \%), а также возможность совмещения работы и домашних обязанностей (18 \%) и более высокий заработок (14 \%). На наш взгляд, гибкость трудовой деятельности и возможность дополнительно зарабатывать - это сильнейшие мотиваторы при выборе данной формы занятости.

Исследуя проблему дефицита общения с коллегами, мы выявили, что только 20 \% сталкиваются с ней, $65 \%$ респондентов дефицита общения не испытывают (рис. 3).

Можно предположить, что большинство дистанционно занятых являются людьми молодого возраста и представляют поколение «Z» (или «цифровое поколение»), которому свойственна новая коммуникативная культура. Вероятно, что такая культура определяет выбор респондентов в пользу дистанционного труда (табл. 2).

Т а б ли ц а 1

Распределение ответов на вопрос «Как Вы очениваете уровень оплаты труда по сравнению со стандартно занятыли, которые выполняют аналогичную работу?», в \%

\begin{tabular}{|l|c|}
\hline \multicolumn{1}{|c|}{ Варианты ответов } & Количество ответивших \\
\hline Наравне & 50 \\
\hline Меньше, чем у стандартно занятых & 14 \\
\hline Больше, чем у стандартно занятых & 22 \\
\hline Затрудняюсь ответить & 14 \\
\hline Итого & 100 \\
\hline
\end{tabular}

Источник: составлено автором.

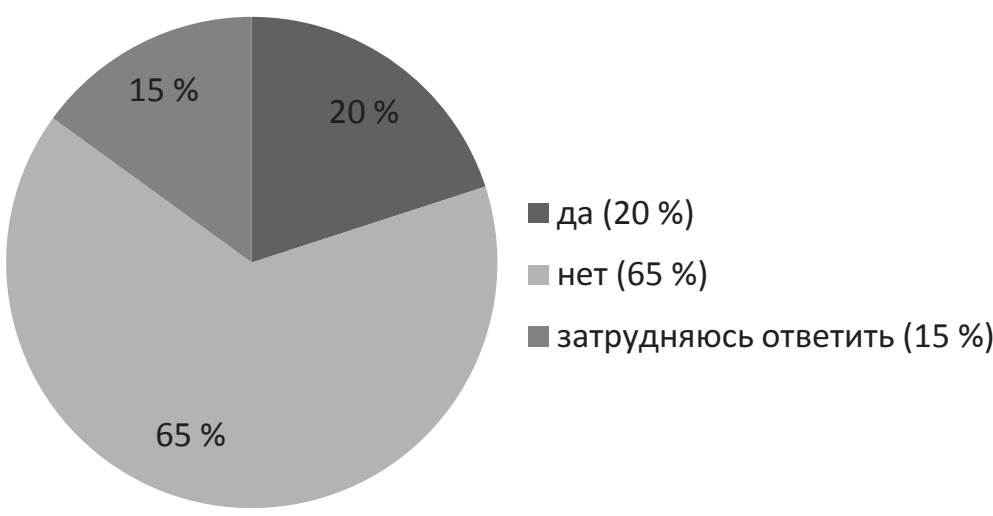

Рuc. 3. Распределение ответов на вопрос «Чувствуете ли Вы нехватку общения с коллегами?», в \% 
В ходе анализа результатов опроса нами была рассмотрена взаимосвязь возраста респондентов с продолжительностью их дистанционной работы (табл. 3).

Дистанционная занятость, которая характеризуется виртуальностью, является для молодых людей более простой в освоении, так как все инструменты её технической реализации им известны. Среди работающих дистанционно в течение 10-15 лет нет людей до 30 лет: это просто объяснить тем, что в данном возрасте немного тех, у кого трудовой стаж составлял бы 10-15 лет. Преимущественно вариант ответа о вовлеченности в дистанционную работу длительностью 10-15 лет выбирали респонденты
45-59 лет (67 \%) и 30-44 лет (33\%). По результатам опроса более 15 лет никто из охваченных респондентов в возрасте 30-59 лет не работал дистанционно. Этот вариант ответа выбрали люди старше 60 лет (это $5 \%$ всей численности опрошенных). Такое распределение ответов можно объяснить тем, что указавшие данный вариант ответа имеют большой опыт работы и, логично, что это более взрослые респонденты.

Также нами была рассмотрена связь между полом респондентов и причинами выбора дистанционной занятости: «дополнительный заработок» и «гибкое рабочее время» (рис. 4).

Полученное распределение, скорее всего, можно пояснить тем, что зачастую женщины вынуж-

Т а б ли ца 2

Распределение ответов на вопрос: «Вам больше нравится работать дистанционно или в режиме стандартной занятости?», в \%

\begin{tabular}{|l|c|}
\hline \multicolumn{1}{|c|}{ Варианты ответов } & Количество ответивших \\
\hline В режиме дистанционной занятости & 70 \\
\hline В режиме стандартной занятости & 11 \\
\hline Для меня нет разницы & 7 \\
\hline Затрудняюсь ответить & 12 \\
\hline Итого & 100 \\
\hline
\end{tabular}

Источник: составлено автором.

Т а б ли и а 3

Связь продолжительности вовлеченности в дистанционную занятость и возраста, \%

\begin{tabular}{|c|c|c|c|c|}
\hline \multirow{2}{*}{ Возраст } & \multicolumn{4}{|c|}{ Продолжительность вовлеченности в дистанционную занятость } \\
\cline { 2 - 5 } & до 5 лет & $5-10$ лет & $10-15$ лет & больше 15 лет \\
\hline До 30 лет & 53 & 42 & - & - \\
\hline 30-44 года & 34 & 50 & 33 & - \\
\hline $45-59$ лет & 11 & 4 & 67 & - \\
\hline Старше 60 лет & 2 & 4 & - & 100 \\
\hline Итого & 100 & 100 & 100 & 100 \\
\hline
\end{tabular}

Источник: составлено автором.

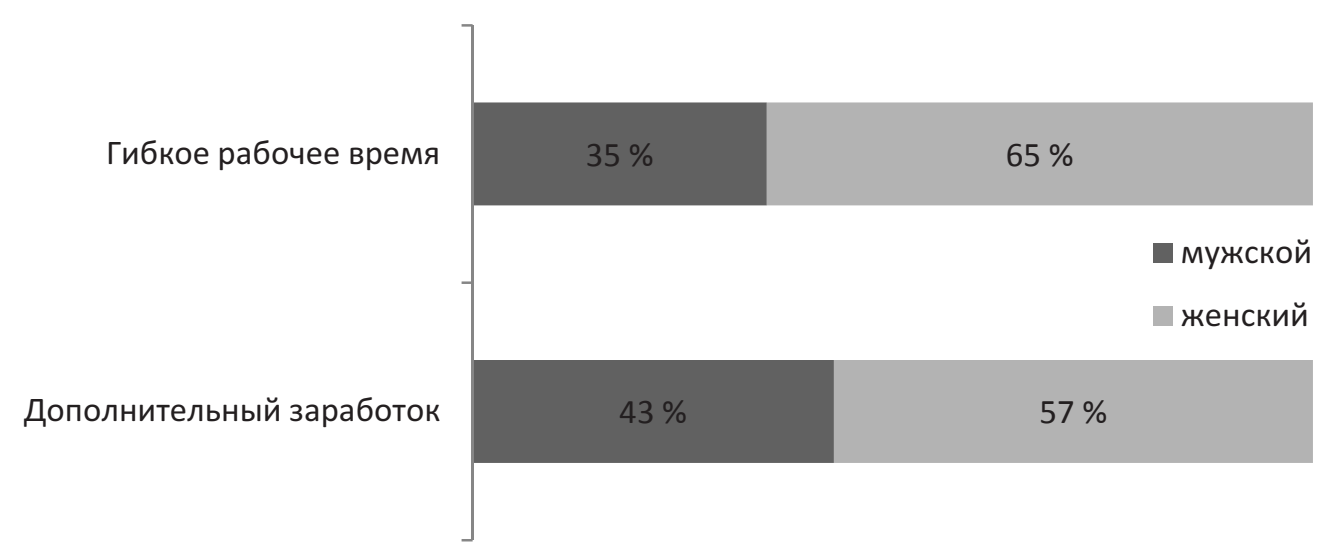

Puc. 4. Связь между полом респондентов и причинами выбора дистанционной занятости «дополнительный заработок» и «гибкое рабочее время», в \% 
дены совмещать выполнение домашних обязанностей, воспитание детей с трудовой деятельностью. Также среди всех опрошенных женщины чуть больше, чем мужчины, недовольны имеющимся уровнем оплаты труда.

Таким образом, по результатам проведенного исследования были сделаны следующие выводы:

- дистанционная занятость - это относительно новое явление для нашей страны (69 \% респондентов вовлечены в дистанционную занятость 5 лет и менее);

- большинство дистанционно занятых являются людьми молодого возраста и представляют поколение «Z» (или «цифровое поколение»), которому свойственна новая коммуникативная культура. Вероятно, что такая культура определяет выбор респондентов в пользу дистанционного труда;

- преимущественно дистанционная занятость распространена в IT-сфере, продажах, сфере финансов, бухгалтерских услуг;

- дистанционная занятость не оформлена трудовым договором более чем у половины опрошенных;

- основные причины выбора этой формы занятости - гибкое рабочее время и дополнительный заработок.

Можно констатировать, что одной из проблем в сфере дистанционного труда является его правовое регулирование. Несмотря на то что регламентации дистанционного труда посвящена статья 49 Трудового кодекса Российской Федерации, дистанционная занятость тем не менее остается преимущественно в теневом секторе экономики, что влечет ряд негативных социально-экономических последствий. Соглашаясь с мнением Н. В. Дороховой, которая пишет, что «за рамками правового регулирования на сегодняшний день остаются многочисленные формы занятости, по тем или иным параметрам отклоняющиеся от утвержденного государством стандарта, отсутствует правовое определение нестандартной занятости населения. Данное обстоятельство служит серьезным препятствием для увеличения гибкости рынка труда, способности отношений занятости населения к самоадаптации», мы констатируем актуальность правовых аспектов управления дистанционной занятостью [3].

Законодательное регулирование вопросов, связанных с внедрением и развитием дистанционной занятости в нашей стране, требует дальнейшего развития и более глубокой проработки, поскольку переход к инновационной модели развития экономики России предполагает развитие нестандартных форм занятости на рынке труда. Как пишет О. А. Ко- лесникова: «Рост числа желающих работать удаленно ведет к повышению востребованности высшего образования. Развитию этой тенденции способствует также стремление Воронежской области, как и России в целом, к информационному обществу, многие атрибуты которого уже присутствуют в нашей жизни» [4]. Следовательно, нужно видеть и понимать положительные эффекты, сопряженные с развитием дистанционного труда.

Существует необходимость разработки механизма регулирования занятости, адекватного современным реалиям и охватывающего все существующие формы нестандартного труда, а также предусматривающего эффективные меры для различных уровней хозяйствования. Сегодня во многих сферах жизни общества актуален процесс децентрализации власти, сил, функций, что приносит положительные результаты. На наш взгляд, политика занятости должна учитывать этот факт и акцентировать внимание на региональном уровне регулирования.

Можно предложить следующие основные направления совершенствования дистанционной занятости в регионе, нацеленные на укрепление дистанционного труда в формальном секторе:

1) развитие дистанционной занятости в рамках социального партнерства;

2) развитие региональной политики трудоустройства и социальной поддержки незанятого населения с помощью дистанционной занятости;

3) внедрение системы мониторинга и статистического учета в области дистанционной занятости;

4) совершенствование и развитие гибкого рынка труда;

5) введение на региональном уровне практики ознакомления граждан и работодателей по вопросам применения дистанционного труда;

6) налаживание исследовательско-аналитической работы по сбору и обработке информации о распространенности и проблемах применения дистанционной занятости в регионе.

Для совершенствования дистанционной занятости нужны определенные мероприятия, соответствующие выявленным тенденциям и проблемам. Эффективным подходом мы считаем децентрализацию власти и функций: именно на уровне региона возможно продуктивное осуществление программ и мероприятий развития занятости, поддержание перспективных форм занятости. Грамотно разрабатывая направления работы, можно создать современный гибкий рынок труда, который даст возможность развития наемным работникам, а также сделает деятельность организаций более эффективной. 


\section{ЛИТЕРАТУРА}

1. Федченко A. A. Трансформация социально-трудовых отношений в цифровой экономике / А. А. Федченко // Вестник Воронежского государственного университета. Серия : Экономика и управление. 2018. № 3. - С. 94 .

2. Одегов Ю. Г. Международная организация труда: 100 лет, что изменилось, а что выдержало проверку временем / Ю. Г. Одегов, Л. С. Бабынина // Вестник Воронежского государственного университета. Серия : Экономика и управление. - 2019. - № 4. - С. 98-106.

Воронежский государственный университет

Дашкова Е. С., доиент кафедры экономики труда и основ управления, кандидат экономических наук, доиент

E-mail:dashkova-82@mail.ru

Звягиниева Валерия Евгеньевна, магистр

E-mail:ms.valeria.v@mail.ru
3. Дорохова Н. В. Организационные условия регулирования адаптивной занятости населения / Н. В. Дорохова // Вестник Воронежского государственного университета. Серия : Экономика и управление. - 2019. - № 3. - С. 76-78.

4. Колесникова О. А. Проблемы и пути реализации эффективной политики занятости населения / О.А.Колесникова // Вестник Воронежского института высоких технологий. - 2019. - № 4 (31). - С. 171175.

Voronezh State University

Dashkova E. S., Associate Professor of the Department of Labor Economics and Management Basics, Candidate of Economic Sciences, Associate Professor E-mail: dashkova-82@mail.ru

Zvyagintseva V. E., Master's Degree E-mail:ms.valeria.v@mail.ru 